\title{
Petrocosmea weiyigangii (Gesneriaceae), a new species from a limestone cave in southern China
}

\author{
F. Wen \\ Guangxi Key Laboratory of Plant Conservation and Restoration Ecology \\ in Karst Terrain, Guilin Botanical Garden, Guangxi Institute of Botany, \\ Guangxi Zhuang Autonomous Region and the Chinese Academy of \\ Sciences, CN-541006, Guilin, Guangxi, China \\ wenfang760608@139.com \\ Gesneriad Conservation Center of China (GCCC), \\ CN-541006, Guilin, Guangxi, China
}

\begin{abstract}
A new species, Petrocosmea weiyigangii F.Wen (Gesneriaceae), is described from southern China. It differs from all other species of Petrocosmea in its deeply lobed leaf blades. It is only known from a limestone cave in northwestern Guangxi, China. Following the IUCN Red List categories and criteria, Petrocosmea weiyigangii is assessed as Critically Endangered.
\end{abstract}

Keywords. Cave-dwelling plant, Gesneriad, Guangxi, IUCN conservation assessments, limestone flora, new taxa, Petrocosmea martini

\section{Introduction}

When Dr Li-Bing Zhang from Missouri Botanical Garden, USA and Prof. Hai He from Chongqing Normal University, China carried out a project on cave-dwelling Polystichum Roth species in October 2010, they found a distinctive species of Gesneriaceae in a large cave from Tianlin County, Guangxi, China. In this plant the leaf blades are lobed for half or more of the width of each side of the blade to the midrib, but not all the way to the midrib. The collectors sent me photos of this plant nearly three years later and I was unable to identify it. In the intervening period, a new species of Primulina Hance, P. multifida B.Pan \& K.F.Chung (Xu et al., 2012), which has a pinnatifid leaf blade margin, was published. The leaves of the unknown species from Tianlin County (Fig. 1A) look rather like those of Primulina multifida (Fig. 1B), leading me to suspect that it may belong to Primulina at that time. In the years that followed, I visited Langping Town, Tianlin County many times but without being able to find the cave and this interesting plant. Fortunately, during a field investigation of the limestone flora of Guangxi, China in May 2018, I accidentally found the cave and the distinctive and attractive diminutive plant with deeply lobed leaves. Luckily it was flowering and the flowers more resembled Petrocosmea Oliv. than Primulina. I was unable to match it to any previously described species of Petrocosmea in the Gesneriaceae collections from Guangxi, Yunnan, Guizhou, Xizang and Sichuan in the principal herbaria in the region (e.g. GXMI, HITBC, IBK, IBSC, KUN, PE). I 


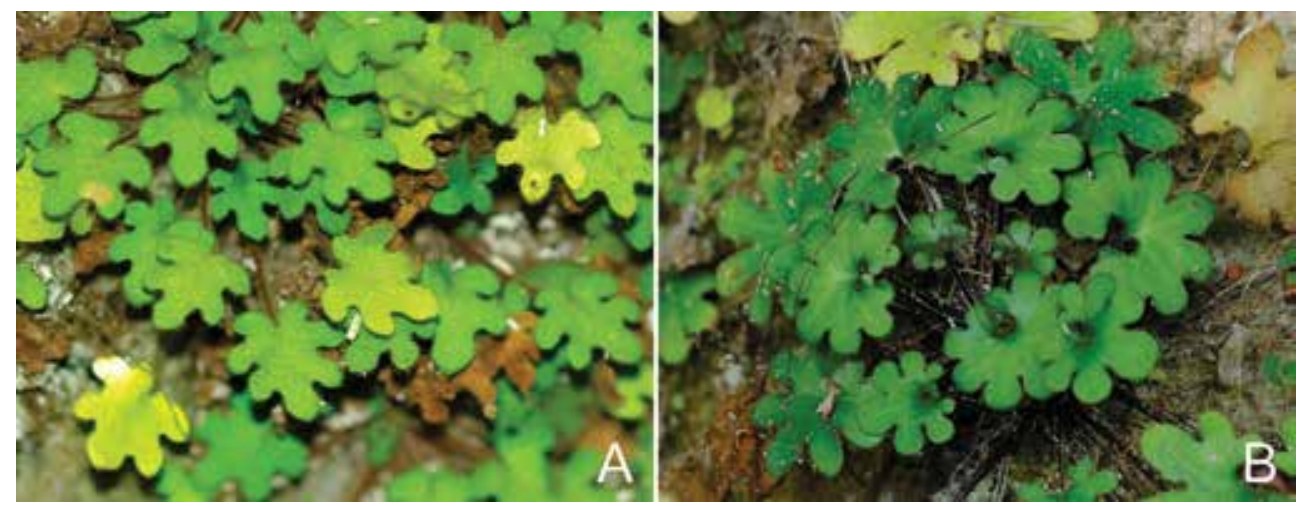

Fig. 1. The similar leaf morphology of A. Petrocosmea weiyigangii F.Wen. and B. Primulina multifida B.Pan \& K.F.Chung. (Photos: F. Wen).

was also unable to match it to any described species of Petrocosmea on comparison to images of specimens available in virtual herbaria (e.g. A, E, K, MO, P), and to descriptions in local floras (Wang et al., 1990, 1998) and monographs (Li \& Wang, 2004; Wei et al., 2010; Qiu et al., 2015a).

Petrocosmea belongs to subtribe Didymocarpinae, tribe Trichosporeae, subfamily Didymocarpoideae of the Gesneriaceae (Weber et al., 2013). The genus currently comprises 47 species in South, East and Southeast Asia (Möller et al., 2016; Qiu et al., 2015a; Wei at al., 2010; Wang et al., 1990, 1998). Almost all Petrocosmea species are found in damp habitats in limestone areas, except $P$. melanophthalma Huan C.Wang et al. (Wang et al., 2013), P. begoniifolia C.Y.Wu ex H.W.Li (Li, 1983, Qiu et al., 2015a), P. chrysotricha M.Q.Han et al. (Han et al., 2018) and P. sinensis Oliv. (Oliver, 1887; Wei et al., 2010; Qiu et al., 2015a), which grow on damp surfaces and in crevices of marble and sandstone rocks and cliffs. All hitherto known species of Petrocosmea have leaf margins that are entire to serrate. The pinnatifid leaf blade margin of this new taxon is the most distinctive feature to distinguish it from other species of Petrocosmea.

The new species is described and illustrated below. A provisional IUCN conservation assessment following the guidelines by the IUCN Standards and Petitions Subcommittee (2017) is also provided.

\section{New species}

Petrocosmea weiyigangii F.Wen, sp. nov.

The deeply lobed margin of the leaf blade distinguishes Petrocosmea weiyigangii F.Wen from all other species of Petrocosmea. - TYPE: China, Guangxi Zhuangzu Autonomous, Tianlin County, Langping town, 243' 'N, 106 ${ }^{\circ} 19^{\prime} \mathrm{E}$, alt. $1330 \mathrm{~m}, 18$ May 2018, flowering, Wei Yi-Gang \& Wen Fang WYG180518-21 (holotype IBK; isotype IBK, KUN). (Fig. 1A, 2-3) 


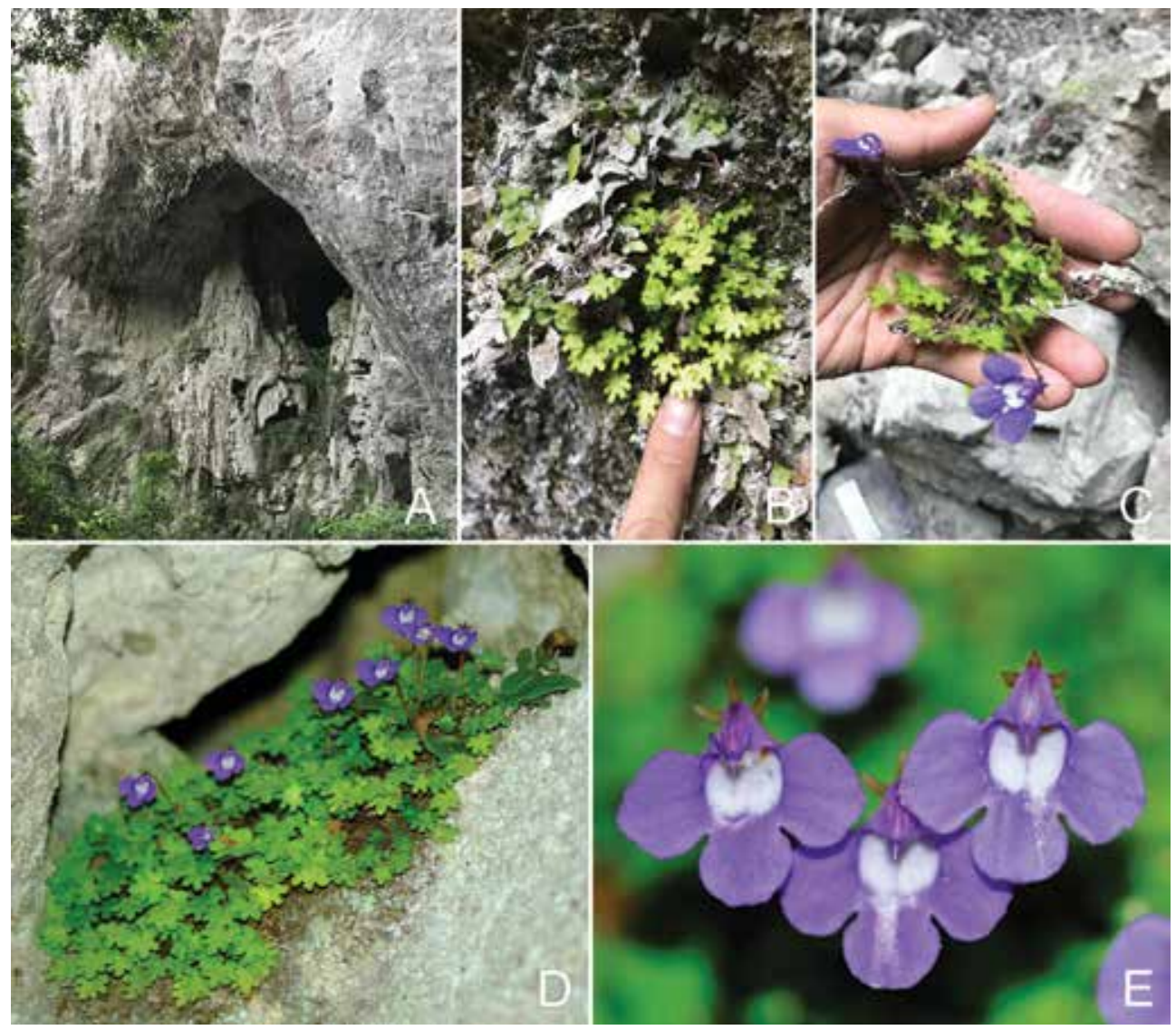

Fig. 2. Petrocosmea weiyigangii F.Wen. A. Habitat. B. Habit, with author's finger for scale. C. Relative size of the adult plant with author's hand for scale. D. Colony of flowering plants. E. Corolla viewed from the front. (Photos: F. Wen).

Perennial, stemless, rosulate herb. Rhizome extremely short, inconspicuous. Leaves inconspicuously spiral, 21 to 30 per plant, petioles subterete, $20-45 \mathrm{~mm}$ long, $0.8-1 \mathrm{~mm}$ in diam., brown, densely puberulent; leaf blades herbaceous when dried, ovate to rounded, slightly asymmetric to symmetric, $12-15 \times 10-12.5 \mathrm{~mm}$, base cordate and truncate, margin deeply lobed, lobes $2-3$ on each side of blade, each lobe narrowly oblong to oblong, apices obtuse to nearly rounded, 2-3-veined, adaxially and abaxially glabrous. Inflorescences axillary, cymes usually 1-flowered; peduncle $35-50 \mathrm{~mm}$ long, densely eglandular-pubescent to pilose; bracts 2 , free and opposite, ensiform, 2-3 $\mathrm{mm}$ long but usually caducous or withered before anthesis; pedicels 6-10 mm long, pubescent. Calyx nearly actinomorphic, equally divided into 5 lobes, with outer surface sparsely pubescent and inner surface nearly glabrous; lobes equal, broadly lanceolate, $6.5-8 \times 3.5-5 \mathrm{~mm}$, margin entire, apex acute. Corolla purple, throat white, sparsely pubescent outside, glabrous inside; tube c. $9 \mathrm{~mm}$ long; adaxial 


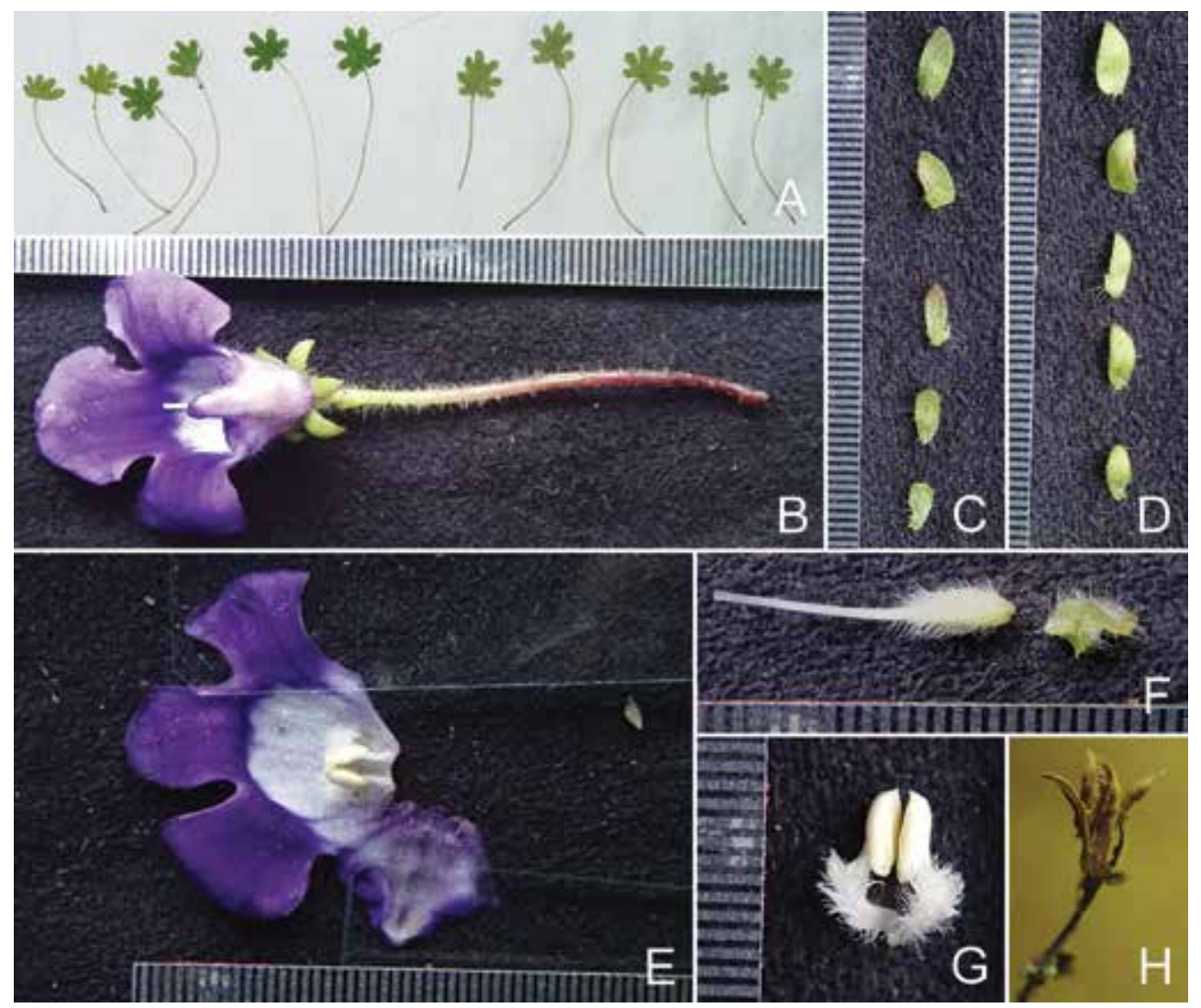

Fig. 3. Petrocosmea weiyigangii F.Wen. A. A variety of leaves. B. Flower viewed from the top. C. Abaxial surfaces of calyx lobes. D. Calyx lobes, adaxial surfaces. E. Corolla, opened up to show stamens and staminodes. F. Pistil (Style, ovary and disc). G. Stamens with glabrous anthers and white pilose filaments. H. Mature dehisced capsule. (Photos: F. Wen).

lip c. $6.5 \mathrm{~mm}$ long, indistinctly 2-lobed with the two small lobes fused for almost their entire length and each lobe folded and rolled laterally to form a carinate-plicate (galeate) structure that encloses the style; abaxial lip c. $19 \mathrm{~mm}$ long, 3-lobed to the middle, with oblong to semicircular lobes. Stamens 2, c. $10 \mathrm{~mm}$ long, adnate to the base of the corolla tube; filaments c. $6 \mathrm{~mm}$ long, geniculate near the middle with an angle of about $150^{\circ}$, white pilose from the base to the middle; anthers ovate, c. 3.6 $\mathrm{mm}$ long, poricidal, glabrous, dorsifixed, coherent at apex; staminodes 3 , adnate to the corolla tube at the base, glabrous. Disc greenish yellow, annular, glabrous, c. 1.5 $\mathrm{mm}$ high. Pistil c. $16 \mathrm{~mm}$ long; ovary densely white villous, ovoid, c. $5.5 \mathrm{~mm}$ long; style semitransparent to white, c. $10.5 \mathrm{~mm}$ long; stigma punctiform, white. Capsules straight in relation to pedicel, brown, long ellipsoid, 5-6 mm long, both loculicidally and septicidally dehiscent. 


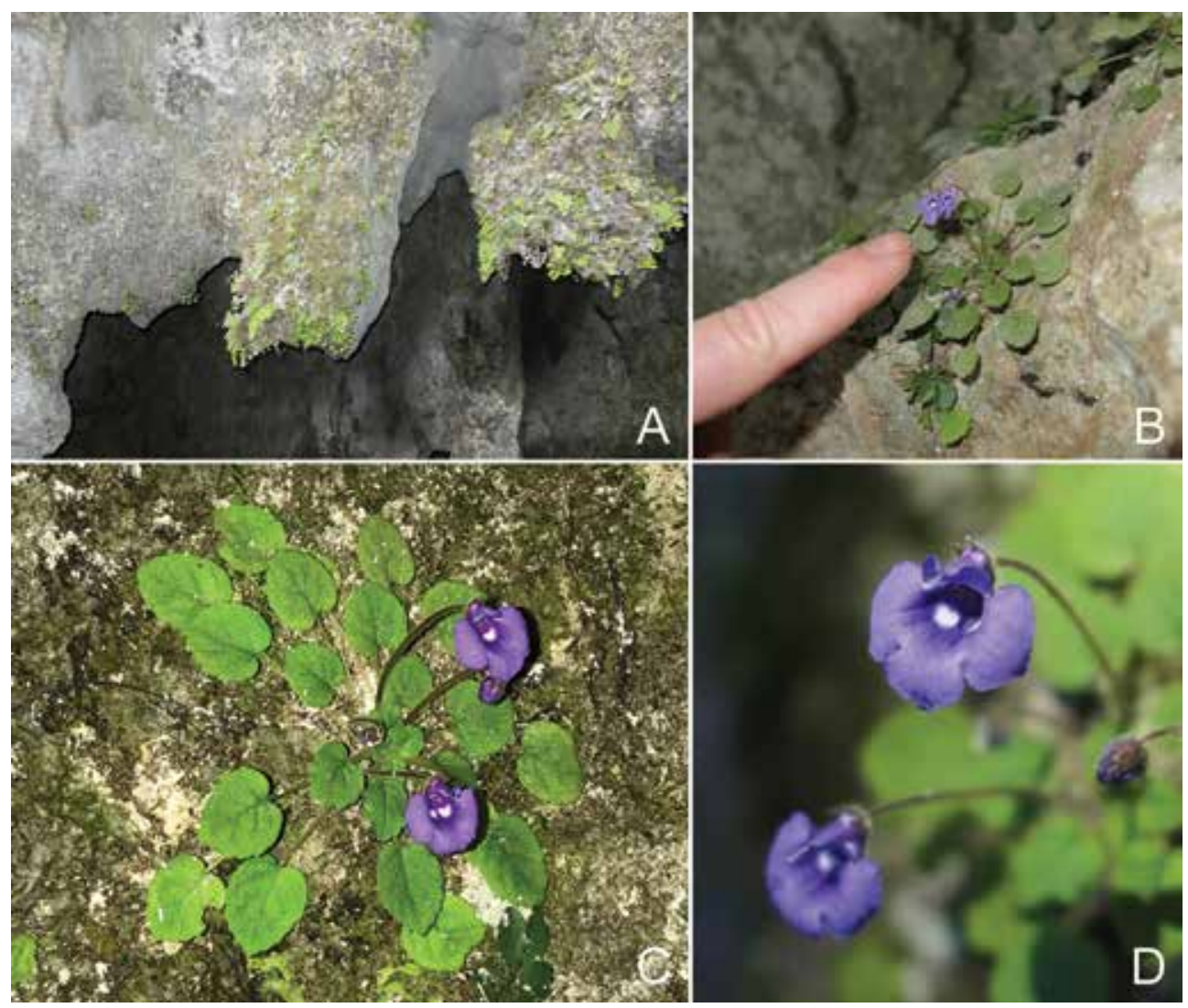

Fig. 4. Petrocosmea martini (H.Lév.) H.Lév. A. Habitat. B. Habit, with author's finger for scale. C. Plant in flower. D. Corolla viewed from the front. (Photos: F. Wen).

Distribution. Only known from the type locality, a large limestone cave, near Tiandong Village, Langping town, Tianlin County, Baise City, Guangxi Zhuangzu Autonomous Region, China (Fig. 2A).

Habitat. The new species is only known from a very small area in the northwestern part of Guangxi, where it has been collected on two occasions growing on damp rock surfaces and in crevices at the bottom of a cliff in a large cave located between 1310 $\mathrm{m}$ and $1330 \mathrm{~m}$ above sea level. Petrocosmea weiyigangii appears to be restricted to shady and damp limestone crevices in near-vertical, moss-covered tufa habitats in the cave (Fig. 1A). The top of cliff above the cave mouth is covered in bushes and trees (Fig. 2A), a similar habitat to many species of Primulina and Petrocosmea martini (Fig. 4).

Etymology. The epithet 'weiyigangii' is coined in honour of the Chinese botanist Prof. Yi-Gang Wei who has discovered, collected and described many new taxa of Gesneriaceae and has contributed much to the study of plant diversity and flora in Guangxi. 
Vernacular names. 毅刚石蝴蝶. The Chinese pronunciation of Petrocosmea weiyigangii is 'Yì Gāng Shí Hú Dié'.

Provisional IUCN conservation assessment. Based on available information, the extent of occurrence (EOO) and area of occurrence (AOO) of Petrocosmea weiyigangii are both estimated at less than $4 \mathrm{~km}^{2}$. The entire population is only known from a single cave which is not in a protected area. This area is subject to human pressure, especially from deforestation and the grazing of goats and cattle. Even if the exact location of the plants is not under direct threat, these local vegetation changes will alter the micro-climate and ecological conditions, thereby impacting humidity and shade and altering the specialised habitat of Petrocosmea weiyigangii. This results in a projected continuing decline in both habitat quality and the number of mature individuals (IUCN Standards and Petitions Subcommittee, 2017). I therefore propose that Petrocosmea weiyigangii should be provisionally assessed as Critically Endangered CR B1ab(iii,v), B2ab(iii,v).

Notes. When this new taxon was first discovered by Dr Zhang and Prof. He, none of the plants were in flower, leading me to suspect it was a Primulina from the photos they sent me. When I observed its flowers and fruits in the field I discovered it possessed a number of characters typical of Petrocosmea: corolla tube broadly tubular and shorter than limb; filaments inserted at base of corolla; no disc; stigma capitate; capsule straight in relation to pedicel, narrowly ellipsoid to oblong to ovoid, nearly as long as calyx, dehiscing loculicidally to base, valves 2 , straight, not twisted. Petrocosmea was previously divided into three sections, namely Petrocosmea sect. Petrocosmea Craib, Petrocosmea sect. Anisochilus Hemsl. and Petrocosmea sect. Deinanthera W.T.Wang (Wang, 1985). Now this genus has been restructured into five sections: those above plus Petrocosmea sect. Minor Z.J.Qiu and Petrocosmea sect. Barbatae Z.J.Qiu based on morphological and molecular evidence (Qiu et al., 2011, 2015a, 2015b). The characters of Petrocosmea sect. Anisochilus include not having constricted anthers, an actinomorphic calyx divided into five segments and the calyx lobe margins entire. There are not many species of Petrocosmea in Guangxi: only $P$. forrestii Craib., P. iodioides Hemsl., P. martini (H.Lév.) H.Lév. and P. minor Hemsl. have previously been recorded. Of all species found in Guangxi, Petrocosmea martini (Fig. 4) is clearly the most similar to $P$. weiyigangii (Table 1). They have a similar floral structure: notably, the upper lip is conspicuously galeate and is about half the length of the lower lip. The flowers of the two species differ in corolla size with the corolla of Petrocosmea weiyigangii larger than P. martini (tube c. $9 \mathrm{~mm}$ long, adaxial lip c. $6.5 \mathrm{~mm}$ long and abaxial lip c. $19 \mathrm{~mm}$ long in $P$. weiyigangii vs. tube c. $3 \mathrm{~mm}$ long, adaxial lip c. $3 \mathrm{~mm}$ long and abaxial lip c. $6.5 \mathrm{~mm}$ long). These floral characters suggest that $P$. weiyigangii belongs to Petrocosmea sect. Anisochilus ser. Iodioides W.T.Wang. Unlike Petrocosmea weiyigangii, P. martini (Fig. 4) is widely distributed on the Yunnan-Guizhou Plateau (including Guizhou and Yunnan provinces and 
Table 1. Morphological comparison of Petrocosmea weiyigangii and P. martini.

\begin{tabular}{|c|c|c|c|}
\hline \multicolumn{2}{|l|}{ Characters } & \multirow{2}{*}{$\begin{array}{l}\text { P. weiyigangii } \\
\text { Ovate to rounded }\end{array}$} & \multirow{2}{*}{$\begin{array}{l}\text { P. martini } \\
\text { Ovate to orbicular-ovate }\end{array}$} \\
\hline 1. Leaf blade & a. Shape & & \\
\hline & b. Margin & $\begin{array}{l}\text { Deeply } 2-3 \text {-lobed on } \\
\text { each side of blade, each } \\
\text { lobe narrowly oblong to } \\
\text { oblong }\end{array}$ & $\begin{array}{l}\text { Crenulate to denticulate, } \\
\text { not lobed }\end{array}$ \\
\hline & c. Indumentum & $\begin{array}{l}\text { Adaxially and abaxially } \\
\text { glabrous }\end{array}$ & $\begin{array}{l}\text { Adaxially pilose, } \\
\text { abaxially densely pilose }\end{array}$ \\
\hline \multicolumn{2}{|c|}{ 2. Calyx lobe shape and size } & $\begin{array}{l}\text { Broadly lanceolate, } \\
6.5-8 \times 3.5-5 \mathrm{~mm}\end{array}$ & $\begin{array}{l}\text { Narrowly lanceolate, } \\
2.5-3 \times 0.8-1.5 \mathrm{~mm}\end{array}$ \\
\hline \multicolumn{2}{|c|}{$\begin{array}{l}\text { 3. Filament length and } \\
\text { indumentum }\end{array}$} & $\begin{array}{l}\text { c. } 6 \mathrm{~mm} \text { long, white } \\
\text { pilose from the base to } \\
\text { the middle }\end{array}$ & $\begin{array}{l}2-3 \mathrm{~mm} \text { long, rusty- } \\
\text { brown puberulent or } \\
\text { glabrous }\end{array}$ \\
\hline \multicolumn{2}{|c|}{ 4. Staminode number } & 3 & 2 \\
\hline \multicolumn{2}{|l|}{ 5. Pistil length } & c. $16 \mathrm{~mm}$ long & $6-8 \mathrm{~mm}$ long \\
\hline \multicolumn{2}{|l|}{ 6. Style length } & c. $10.5 \mathrm{~mm}$ long & $1.5-2 \mathrm{~mm}$ long \\
\hline
\end{tabular}

northwestern Guangxi). The distribution of Petrocosmea weiyigangii is entirely within the range of distribution of $P$. martini (Fig. 5) and they are likely to be closely related with the unique morphological features of the former due to adaptation to its special cave environment or by the long geological isolation (Monro et al., 2018; Tao et al., 2015).

ACKNOWLEDGEMENTS. I thank Stephen Maciejewski and Dr David J. Middleton for checking the manuscript, and Dr. Li-Bing Zhang from Missouri Botanical Garden, U.S.A. and Prof. Hai He from Chongqing Normal University, China for providing useful information on this species and the cave. This study was financially supported by the Guangxi Key Laboratory of Plant Conservation and Restoration Ecology in Karst Terrain (17-259-23); the Natural Science Foundation of Guangxi (2017GXNSFAA198006); Guangxi science and technology project (Guike AB16380053); the STS Programme of the Chinese Academy of Sciences (KFJ-3W-No1); Science Research Foundation of Guangxi Academy of Sciences (2017YJJ23022); and the National Natural Science Foundation of China (31460159 \& 31860047). 


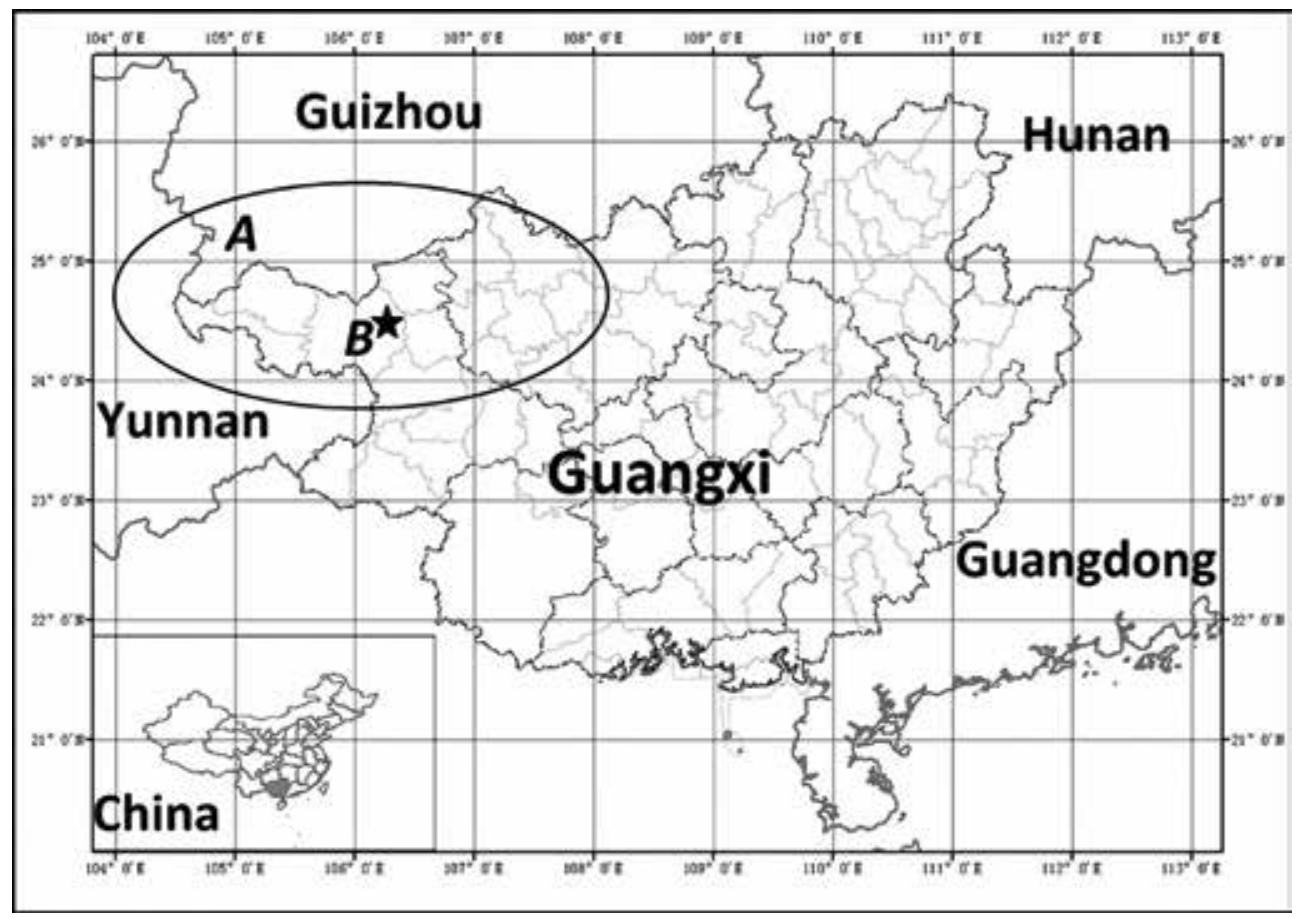

Fig. 5. Distribution of Petrocosmea weiyigangii F. Wen ( $\star$ ), marked as 'B', and its relative, P. martini (H.Lév.) H.Lév. (in the elliptical area, marked as 'A') in China.

\section{References}

Han, M.Q., Yuan, Q., Lü, T.F., Jiang, H. \& Liu, Y. (2018). Petrocosmea chrysotricha sp. nov. (Petrocosmea, Gesneriaceae), a species previously mistaken for P. begoniifolia on marlstone cliffs in Yunnan, China. Nordic J. Bot. 36(4): njb-01664.

IUCN Standards and Petitions Subcommittee (2017). Guidelines for Using the IUCN Red List Categories and Criteria, Version 13. Prepared by the Standards and Petitions Subcommittee. Available from http://www.iucnredlist.org/documents/ RedListGuidelines.pdf.

Li, H.W. (1983). Notulae de Gesneriaceis Yunnanensibus. Bull. Bot. Res., Harbin 3: 19-27.

Li, Z.Y. \& Wang, Y.Z. (2004). Boeica. In: Li, Z.Y. \& Wang, Y.Z. (eds) Plants of Gesneriaceae in China, pp. 154-166. Zhengzhou: Henan Science and Technology Publishing House.

Möller, M., Wei, Y.G., Wen, F., Clark, J.L. \& Weber, A. (2016). You win some you lose some: updated generic delineations and classification of Gesneriaceae - implications for the family in China. Guihaia 36: 44-60.

Monro, A.K., Bystriakova, N., Fu, L.F., Wen, F. \& Wei, Y.G. (2018). Discovery of a diverse cave flora in China. PLoS ONE 13(2): e0190801.

Oliver, D. (1887). Petrocosmea sinensis Oliv. In: Hooker, W.D. (ed.) Icones Plantarum, vol. 18, pl. 1716. London: Longman.

Qiu, Z.J., Yuan, Z.L., Li, Z.Y., \& Wang, Y.Z. (2011). Confirmation of a natural hybrid species in Petrocosmea (Gesneriaceae) based on molecular and morphological evidence. J. Syst. Evol. 49 (5): 449-463. 
Qiu, Z.J., Liu, Z.Y., Pang, H.B., Song, C.F., Zhang, J., Li, Z.Y., Wang, Y.Z., Lu, Y.X., Xie, L.S., Xie, R.X., Yang, P., Tan, X.L., Peng, Y., \& Qian, Q.N. (2015a). Plants of Petrocosmea in China. China: Science Press.

Qiu, Z.J., Lu, Y.X., Li, C.Q., Dong, Y., Smith, J.F., \& Wang, Z.Y. (2015b). Origin and evolution of Petrocosmea (Gesneriaceae) inferred from both DNA sequence and novel findings in morphology with a test of morphology-based hypotheses. BMC Plant Biol. 15(1): 167.

Tao, J.J., Qi, Q.W., Kang, M. \& Huang, H.W. (2015). Adaptive Molecular Evolution of PHYE in Primulina, a Karst Cave Plant. PLoS ONE 10(6): e0127821.

Wang, H.C., Zhang, L.B. \& He, Z.R. (2013). Petrocosmea melanophthalma, a new species in Section Deianthera (Gesneriaceae) from Yunnan, China. Novon 22(4): 486-490.

Wang, W.T. (1985). The second revision of the genus Petrocosmea (Gesneriaceae). Acta Bot. Yunnan. 7(1): 49-68.

Wang, W.T., Pan, K.Y., Zhang, Z.Y. \& Li, Z.Y. (1990). Gesneriaceae. In: Wang, W.T. (ed.) Flora Reipublicae Popularis Sinicae, vol. 69. Beijing: Science Press.

Wang, W.T., Pan, K.Y., Li, Z.Y, Weitzman, A.L. \& Skog, L.E. (1998). Gesneriaceae. In: Wu, Z.Y. \& Raven, P.H. (eds) Flora of China, vol. 18, pp. 244-401. Beijing, China: Science Press and St. Louis, Missouri, USA: Missouri Botanical Garden Press.

Weber, A., Clark, J.L., \& Möller, M. (2013). A new formal classification of Gesneriaceae. Selbyana 31(2): 68-94.

Wei, Y.G., Wen, F., Möller, M., Monro, A., Zhang, Q., Gao, Q., Mou, H.F., Zhong, S.H. \& Cui, C. (2010). Gesneriaceae of South China. Nanning, China: Guangxi Science and Technology Publishing House.

Xu, W.B., Pan, B., Liu, Y., Peng, C.I. \& Chung, K.F. (2012). Two new species, Primulina multifida and P. pseudomollifolia (Gesneriaceae), from karst caves in Guangxi, China. Bot. Stud. 53: 165-175. 